\title{
World of Warcraft, the aftermath: How game elements transfer into perceptions, associations and (day)dreams in the everyday life of massively multiplayer online role-playing game players.
}

\section{Citation for published version (APA):}

Poels, K., IJsselsteijn, W. A., \& Kort, de, Y. A. W. (2015). World of Warcraft, the aftermath: How game elements transfer into perceptions, associations and (day)dreams in the everyday life of massively multiplayer online roleplaying game players. New Media \& Society, 17(7), 1137-1153. [7]. https://doi.org/10.1177/1461444814521596

\section{Document license:}

TAVERNE

\section{DOI:}

$10.1177 / 1461444814521596$

Document status and date:

Published: 01/01/2015

\section{Document Version:}

Publisher's PDF, also known as Version of Record (includes final page, issue and volume numbers)

\section{Please check the document version of this publication:}

- A submitted manuscript is the version of the article upon submission and before peer-review. There can be important differences between the submitted version and the official published version of record. People interested in the research are advised to contact the author for the final version of the publication, or visit the $\mathrm{DOI}$ to the publisher's website.

- The final author version and the galley proof are versions of the publication after peer review.

- The final published version features the final layout of the paper including the volume, issue and page numbers.

Link to publication

\footnotetext{
General rights

- You may freely distribute the URL identifying the publication in the public portal. follow below link for the End User Agreement:

www.tue.nl/taverne

\author{
Take down policy \\ If you believe that this document breaches copyright please contact us at: \\ openaccess@tue.nl \\ providing details and we will investigate your claim.
}

Copyright and moral rights for the publications made accessible in the public portal are retained by the authors and/or other copyright owners and it is a condition of accessing publications that users recognise and abide by the legal requirements associated with these rights.

- Users may download and print one copy of any publication from the public portal for the purpose of private study or research.

- You may not further distribute the material or use it for any profit-making activity or commercial gain

If the publication is distributed under the terms of Article 25fa of the Dutch Copyright Act, indicated by the "Taverne" license above, please 
World of Warcraft, the aftermath: How game elements transfer into

perceptions, associations and (day)dreams in the everyday life of massively multiplayer online role-playing game players
2015, Vol. 17(7) II37-II53

(C) The Author(s) 2014

Reprints and permissions:

sagepub.co.uk/journalsPermissions.nav DOI: 10.1 |77/|46|4448|452I596

nms.sagepub.com

@SAGE

\title{
Karolien Poels
}

University of Antwerp, Belgium

\section{Wijnand A ljsselsteijn}

Eindhoven University of Technology, The Netherlands

\section{Yvonne de Kort}

Eindhoven University of Technology, The Netherlands

\begin{abstract}
This paper describes the phenomenon of game-biased perceptions and associations, or how, through intensive game play, elements from the game world can trigger thoughts and imagery outside the game world, influencing the perception and interpretation of stimuli in everyday life. Examples include the insertion of game elements in thoughts, perceptions and dreams, the use of specific vocabulary or slang - typical to the game world - in everyday conversations, and the association of real-life objects with game elements. Results from an online survey with habitual players of World of Warcraft confirm the existence of this phenomenon and show that the occurrence of these
\end{abstract}

\section{Corresponding author:}

Karolien Poels, Department of Communication Studies, University of Antwerp, Sint Jacobstraat 2, 2000 Antwerpen, Belgium.

Email: karolien.poels@uantwerpen.be 
game-biased perceptions and associations is reinforced by increasing playing time and narrative involvement.

\section{Keywords}

Digital games, massively multiplayer online role-playing game, perception, player involvement, real life

\section{Introduction}

In Vladimir Nabokov's 1929 novel The Defense, we learn how the novel's main character, Aleksandr Ivanovich Luzhin, a chess Grandmaster, becomes obsessed with the game of chess and eventually suffers a nervous breakdown during a tournament against one of his main competitors. After his doctor convinces him that it is his single-minded obsession with the game that is the main reason for his mental breakdown, Luzhin unsuccessfully attempts to abandon all thoughts of chess. In what follows, we are witness to how every element of his life is suffused with the game. Luzhin perceives the familiar tiled black and white pattern everywhere, in courtyards' flagstones, bathroom tiling and patterned tablecloths. He interprets relationships between everyday objects within the rules and structures of the game (e.g., "The urns that stood on the stone pedestals at the four corners of the terrace threatened one another across their diagonals"). These rules also govern his own physical movements, for example, estimating how he could get to his destination using only Knight's tours. Luzhin's madness does not subside and eventually ends dramatically with his suicide, which he had previously announced to his wife by his "need to leave the game". Whereas Nabokov's character Luzhin is fictional (although inspired by the life and death of the German chess master Curt von Bardeleben) and suffers from severe mental illness, the phenomenon of a game influencing our perception of reality - its rules, patterns, and objects transferring to everyday thoughts and perceptions - is not alien to avid players of digital games. The current paper investigates the nature and extent of this phenomenon.

A substantial part of digital gaming research has focused on what happens after game play. These studies typically intend to reveal the positive or negative impact of digital games, with the goal of getting insights in the personal, societal, educational or economical relevance of playing games. In this regard, there is a lively debate going on investigating negative after-effects of playing digital games, for example, the interplay between playing violent games and aggressive behaviour (Carnagey and Anderson, 2005; Ferguson, 2007, 2010). In addition, several studies have focused on the positive aftereffects of gaming, such as heightened attention to visual cues (Dye et al., 2009; Green and Bavelier, 2003, 2007), bonding with friends (Cole and Griffiths, 2007; Steinkuehler and Williams, 2006) or training of professional and leadership skills (Reeves et al., 2008; Yee, 2006b). Further, research based on cultivation theory has studied the effect of playing digital games on estimations and attitudes towards real-world situations, such as the occurrence of violence and dangers (Van Mierlo and Van den Bulck, 2004; Williams, 2006). Less is known, however, about how playing digital games affects the daily life of 
the players in subtler, perhaps even more mundane, ways. To put it differently, does playing digital games influence or alter the perception and experience of everyday life, such as the things we see, the words we use, our fantasies or (day)dreams?

There is reason to assume that (elements of) digital game play can linger in players' minds after they turned off the gaming device. In the early 1990s, when Tetris (Pajitnov, 1984) was tremendously popular, journalist Annette Earling (1996) reported about the Tetris Effect. This effect was described as "a tendency to identify everything in the world as being made of four squares and to attempt to determine where it fits in" (Kidd, 1996). Discussions on several game forums testify that many players recognize this effect. Surprisingly, the Tetris effect received only scant attention in academic research. A notable exception in this regard is the study by Stickgold et al. (2000), who showed that people playing Tetris reported seeing falling blocks in the hypnagogic phase of their sleep (i.e., the first stage of the sleeping process, right before falling asleep). Moreover, they found that even amnesics (i.e., people who have deficiencies in the memory part of their brain) reported the Tetris effect (without remembering playing Tetris). Is it the simplicity or the repetitive nature of Tetris that causes marks in our mental system or is it the deep immersion in the game play? And does this phenomenon extend to more recent, highly immersive game environments in which many players are currently engaged? In this study we focus on massively multiplayer online role-playing games (MMORPGs) as one particular and very immersive game genre (Williams, 2006; Yee, 2006a). We posit that for players who repeatedly and intensively engage in MMORPGs, elements from the game world are likely to bias their perceptions and associations in the real world. To explain this we are inspired by the concept of brain plasticity (Kolb and Whishaw, 1998), basic human perceptual processes (e.g., Gregory, 1970) and specific findings related to the interplay between media use and everyday life. We hypothesize that for habitual players of MMORPGs, their experience and knowledge from the game environment become a mental template that influences the perception and interpretation of real-life environmental stimuli. Examples could be seen in the perception of objects, or sounds in the real world being biased by objects typical to the game world, language and expressions used in the game world that show up in everyday vocabulary, daydreams, hypnagogic experiences or regular nocturnal dreams about the game.

We first explain why MMORPGs are a game genre in which this phenomenon is most likely to occur. Next, we propose processes through which these biased perceptions and interpretations are established and specify in which everyday life domains we expect them to manifest themselves. This is followed by a description of our concrete hypotheses that are subsequently tested in a large-scale survey with habitual players of World of Warcraft (WoW), the most popular MMORPG. We end with a discussion of the results found and how they contribute to the field of digital gaming research.

\section{Theoretical background}

\section{The MMORPG as an immersive game environment}

Nowadays millions of people all over the world play MMORPGs and interactively control their avatar, or player character, in three-dimensional virtual game worlds, such as 
WoW (Blizzard Entertainment, 2004), EVE Online (CCP Games, 2003), League of Legends (Riot Games, 2009) or Minecraft (Mojang, 2009). Previous studies have shown that players take virtual MMORPG worlds very seriously and derive salient emotional experiences from them (Yee, 2006a). MMORPGs can be seen as huge online and persistent worlds filled with thousands of avatars, controlled by individual people, who interact with each other and with computer-controlled characters, also referred to as non-player characters (NPCs). For most MMORPGs, the aim is to acquire as much power as possible for your avatar, which can be achieved by winning fights or completing quests against or together with NPCs or human-controlled avatars. A typical MMORPG environment is built around a very rich and extensive fantasy world, involving countless locations to move your avatar to. MMORPGs require their players to engage frequently and repeatedly in the game. A large-scale study among American MMOPRG players showed that on average they spend 22 hours per week playing their favourite game (Yee, 2006c). A more recent study from Williams et al. (2008) reported an average playing time of 25.86 playing hours a week. Moreover, MMORPGs contain elaborate narratives with which the player needs to become acquainted in order to successfully complete the goals set by the game. Players usually have to find out things about the specific game story or can add their own sub-stories to complement the general storyline. Studies have found that one of the most important motivations to engage in playing MMORPGs is immersion, which refers to the exploration of the game world and the game narratives (i.e., history, storyline, characters), as well as the ability to escape from daily life and hassles (Williams et al., 2008; Yee, 2006c). Immersion is one of the most prominent game experiences associated with playing digital games in general (Ermi and Mäyrä, 2005; Jennett et al., 2008; Poels et al., 2012). According to Jennett et al. (2008), immersion differs from other engaging game experiences, such as flow, presence and cognitive absorption. Although immersion contributes to having a good game experience, it does not necessarily need to be an optimal or fulfilling experience (Jennett et al., 2008). In this way, it differs from flow, which typically refers to that optimal experience (Csikszentmihalyi, 1990). As a game experience, immersion is then defined as the psychological experience of being drawn into an alternative reality, being involved with all senses in the game, and blocking out sensory input from the outside world. Given the fact that players of MMORPGs play on a very regular basis, spend hours in the game world and experience high levels of immersion due to the rich fantasy world and specific narratives with which players familiarize, the genre entails high levels of player involvement (Calleja, 2007, 2011). In the current study we rely on the work of Calleja (2011) and study one particular aspect of player involvement: narrative involvement, or immersion into the narratives and story of the game.

\section{Game-biased perceptions and associations}

Although the current study will not focus on differences in brain structures of MMORPG players versus non-players, the concept of brain plasticity does provide a basic mechanism as to how intensive and frequently repeated activities can influence people's perceptions and interpretations of their environment. Brain studies have confirmed that if people are immersed in particular activities and perform them 
repeatedly, frequently and over long periods of time, the brain adapts its neural structure and accordingly creates an increased sensitivity for these recurring stimuli, to efficiently deal with them in the future (Kolb and Whishaw, 1998; Munte et al., 2002). The flexibility of the brain circuitry to constantly adjust as a function of experiences is known as brain plasticity and has been well established as a central concept in the neurosciences (for a review, see Kolb and Whishaw, 1998). There are numerous examples of structural changes in brain circuitry as a consequence of extensive experience. For example, studies using functional magnetic resonance imaging (fMRI) brain scans have shown that some areas in the brains of professional musicians, who spend multiple hours a day playing their favourite instrument, are larger than similar areas in the brain of non-musicians (Munte et al., 2002). In a well-publicized study, Maguire et al. (2006) demonstrated that London taxi drivers have a larger hippocampus (a region of the brain specialized in acquiring and using complex spatial information in order to navigate efficiently) than London bus drivers, who were matched for driving experience and levels of stress, but differed in that they follow a constrained set of routes.

Applying this to playing MMORPGs, we expect that - due to their immersive nature combined with the fact that players spend a lot of time in these game worlds and are thus repeatedly and frequently exposed to the game - elements from the virtual game world are transferred to the players' perceptual and experiential mental system. As a consequence, their perception and interpretation of real-life environments will be (partly) shaped by the game environments. In the remainder of this paper we refer to this phenomenon as game-biased perceptions and associations. Based on specific literature on perceptions, experiences and media use, and on empirical data from an earlier focus group study (Poels et al., 2010), we propose five domains in which game-biased perceptions and associations are expected to occur.

Physical objects. Research in the field of perception has found that the way we perceive our environment is affected by our concepts, beliefs and expectations (Gregory, 1970). Vision scientists call the way we are primed to see things in a particular context our perceptual set. This process has been empirically illustrated by experiments showing that the interpretation of ambiguous figures or blurred images depends on the situational context respondents are in (Boring, 1930; Bruner and Potter, 1964; Bugelski and Alampay, 1961). For example, Bugelski and Alampay (1961) showed that an ambiguous figure open to interpretation to be "a rat" or "a man with spectacles" was more likely to be interpreted as being "a rat" by people who had just been exposed to drawings of other animals, whereas the reverse was true for people who had just seen drawings of other people. The above-mentioned studies typically focus on situational activation of a specific context, such as being primed with animals versus people. We expect that if players are repeatedly exposed to a specific kind of (fantasy) game environment, their subsequent interpretation of the real world can be biased accordingly. One of the most notable examples of this domain, described in an earlier focus group study (Poels et al., 2010), was a WoW player telling that the first thing that comes to his mind when seeing the signposts on the university campus were the signposts in WoW indicating the way to Stormwind and Ironforge. 
Sounds and music. In a similar vein, we expect that particular sounds or music heard in real life can be interpreted based on their meaning in the game world. Hearing a particular piece of music can bring about associations with a specific event (Cohen, 1998). For example, a song played at a funeral can bring back lively memories of that funeral, and of the deceased person. Moreover, people infer meaning from music based on the context in which they most frequently hear it (Cohen, 1998). Applied to music or sounds in the context of digital gaming, we expect that music heard in the game or played while gaming can trigger lively memories of the game world, when hearing it in daily life. Moreover, particular sounds heard in real life (e.g., the sound of car wheels skidding), which are also present in the game world, can be interpreted by players based on the meaning they have in the context of the game (e.g., a car race).

Vocabulary and expressions. Many digital games contain game-specific expressions and vocabulary and players often use this game-related slang based on the words they use when interacting with each other in the game. Notable examples are "N00B", a newbie in a game, and "WTF!", an abbreviation of the expression "what the f*ck". WoW even has its own slang dictionary: www.wowslang.com. The use and choice of words and expressions is often linked to a person's age, sex, personality and social identity, and can be influenced by several contextual factors (Pennebaker et al., 2003). Ethnographic studies have highlighted the importance of language in studying social virtual worlds, such as Second Life (Boellstorff, 2008), and social digital game worlds, such as WoW (Nardi, 2010). Also, a specific use of language and vocabulary, also referred to as "argot", is one of the elements characterizing subcultures (Brake, 1980). Participants from the focus groups described by Poels et al. (2010) recognized the use of game-related words in everyday conversations, such as the word "N00B" or using the "gold" from WoW to indicate money in real life. Interestingly, recent attention to gamification (i.e., the application of game-related principles to non-game contexts) has explicitly introduced game-related terminology to everyday situations of, for instance, work performance, physical exercise and educational achievement. Game-related terms such as "levelling up" or "achievement badges" are thus becoming more commonplace in our everyday language. However, we do not regard this conscious effort to harness the motivational power of digital games in everyday life as part of the phenomenon of game-biased perceptions and associations, as addressed in the current paper.

Daydreams. Daydreaming involves fantasizing about hopes or ambitions while being awake (Klinger, 1990). Repeated and frequent media use can influence daydreaming. For example, a longitudinal study by Valkenburg and Van der Voort (1995) showed that TV viewing during year 1 had an influence on daydreaming in year 2 for young children (8-12 years old). A recent study showed that engagement in digital games was positively correlated with "positive-constructive daydreaming", or daydreaming related to enjoyment and assisting in problem solving (Dauphin and Heller, 2010). In the focus group study of Poels et al. (2010), participants mentioned daydreaming about their favourite game, both in the context of tactics, and in the context of social interactions taking place in the game. 
Nightly dreams. Besides biasing perception and associations during the waking hours, intense immersion in a game world can also have an impact on nocturnal dreams. In a widely cited study, Stickgold et al. (2000) argued that when people engage in stimulating activities for longer periods of time, they often experience a replay of these activities in the early phases of their sleep. Their study showed that intensively playing the digital game Tetris influences nightly dreams. Participants in their study reported images of falling Tetris pieces, and rotating them into empty spaces occurring in their dreams. In this context, Gackenbach (2006) and Van den Bulck (2004) also found elements from digital games to show up in dreams.

\section{Hypotheses development}

MMORPGs require intensive game play. This means, in order to fully enjoy the game, players have to engage with the game world frequently and over a long period of time. Moreover, MMORPGs cater for high levels of player immersion, due to their rich environment and storylines. As previously discussed, studies on brain plasticity and basic perception theory have shown that intensive activities performed frequently and for long periods of time can bias our perception and experience of our surroundings. Since playing MMORPGs is an intensive experience, we formulated (partly based on previous findings from a focus group study) five domains in which we expect game-biased perceptions and associations to occur. Combining all these findings, we posit the central hypothesis of this paper as follows:

Hypothesis 1: Players of MMORPGs have biased perceptions and associations stemming from the game environment in the following domains: (1) objects; (2) sounds and music; (3) vocabulary and expressions; (4) daydreams; and (5) nightly dreams. UL

Evidently, there will be variation in the degree to which different MMORPG players engage in intensive game play. For this reason we extend our central hypothesis, taking into account two parameters we expect to be related to the occurrence of game-biased perceptions and associations, namely playing time and narrative involvement. Playing time should be interpreted as a quantitative measure for shaping game-biased perceptions and interpretations. An increase in playing time implies more exposure to the game environment. This leads to the second hypothesis:

Hypothesis 2: The occurrence of game-biased perceptions and experiences is strengthened with increasing playing time.

Above this, narrative involvement, defined as the engagement with the designed or scripted narrative and the personal interpretation and experience thereof (Calleja, 2007, 2011), is a qualitative measure leading to more intensive game play and potentially more pronounced manifestations of the game-biased perceptions and associations as outlined above. This leads to the third hypothesis: 
Hypothesis 3: The occurrence of game-biased perceptions and experiences is strengthened with increasing narrative involvement.

\section{Method}

\section{Design, procedure and measures}

We set up an online survey targeted to players of the MMORPG WoW. This game was released in 2004 by Blizzard Entertainment and is the most popular MMORPG worldwide, with more than 11.1 million active subscriptions in 2011 (Gamasutra, 2011). Because of the intensive game play and the elaborate storyline, WoW is well suited for testing the main hypotheses of this paper. The survey was created through an online survey tool: SurveyMonkey (www.surveymonkey.com). The invitation to participate contained a URL that directly guided the participants to the beginning of the survey. The survey began with a welcoming page stating that we wanted to explore how players experience their game and how this affects their experiences in day-to-day life. On the following pages, there were statements related to the target variables of our study: participants' narrative involvement with WoW (two items): (1) I am familiar with the story on which my game is based; (2) I have taken time to get acquainted with the lore and story behind my game $(r=.53, p<$ .001 ), and a set of statements for each of the five dimensions on which we expected biased perceptions and experiences to occur (see Table 1 for all statements). All these statements were measured with five-point Likert scales ranging from totally disagree (1) to totally agree (5), with a neutral (3) as the midpoint of the scale. The survey ended with questions about playing frequency (e.g., the number of hours they played the game on an average day during the last 3 months), their general media use (TV, Internet, books, movies) and a list of typical socio-demographic questions. It took 15 minutes to complete the survey.

\section{Participants}

Participants were solicited via two of the most frequented WoW fora (http://forums.worldofwarcraft.com/and http://wow.allakhazam.com/). A total of 511 participants completed the survey: 441 male and 69 female participants (one missing). Their ages ranged from 12 to 71 years $\left(M_{\text {age }}=24.39 ; S D=9.14\right)$. The sample was international, including participants from the United States $(n=125 ; 24.45 \%$ of the total sample), United Kingdom ( $n$ $=124 ; 24.27 \%$ of the total sample), The Netherlands ( $n=50 ; 9.78 \%$ of the total sample), Sweden $(n=40 ; 7.83 \%$ of the total sample), Denmark $(n=31 ; 6.07 \%$ of the total sample), Finland ( $n=20 ; 3.91 \%$ of the total sample) and 30 other countries. Participants' WoW playing frequency ranged from one playing hour to 16 playing hours on an average day $(M=4.47$ hours, $S D=2.63$ hours $)$. All participants took part on a voluntary basis and did not receive any incentive or compensation.

\section{Results}

We first checked whether the five dimensions of biased perceptions and experiences we deduced from literature and an earlier focus group study could be empirically 
Table I. Factor analysis (rotated component matrix) for the factor analysis on the items of game-biased perceptions and associations.

\begin{tabular}{lllllll} 
Game-biased perceptions and associations & \multicolumn{4}{l}{ Factor loadings } \\
\cline { 2 - 7 } & I & II & III & IV & V
\end{tabular}

Physical objects

- Certain places, settings or situations I

encounter in daily life can remind me of some "game element".

- Certain people I encounter in daily life remind me in one way or another of characters I meet in my game.

- Certain objects I come across in daily life can remind me of some "game element".

- I am never reminded of any element I know from my game, after I turn off the game.

- I can't think of any normal object from daily life, which reminds me of some game (element) when I encounter it.

Daydreams

- When I am not playing computer games, elements of certain games still show up in my thoughts.

- I never daydream about my game when I'm not playing it.

- When I am bored, I dream and fantasize about things related to my game.

- I like daydreaming and fantasizing about computer games in general.

Nightly dreams

- Elements of my game can show up in dreams I have at night.

- I never dream about computer games.

- I sometimes notice the theme of my dreams or the kinds of things I dream about, being like something I know from my game.

- Elements of my game tend to get blended into my dreams, when I am dreaming about other stuff.

Sounds and music

- There are certain songs or music passages that trigger lively memories I have from a game I played in the past.

- Certain sounds or songs I hear in real life remind me of a certain computer game.

- I don't know of any sounds or music passages that give me an instant flashback to a moment in some computer game, or the emotion connected to that gaming moment. 
Table I. (Continued)

\begin{tabular}{|c|c|c|c|c|c|}
\hline \multirow[t]{2}{*}{ Game-biased perceptions and associations } & \multicolumn{5}{|c|}{ Factor loadings } \\
\hline & 1 & II & III & IV & $\mathrm{V}$ \\
\hline $\begin{array}{l}\text { - Certain songs or sounds in daily life make me } \\
\text { want to play a certain computer game. }\end{array}$ & & & & & .660 \\
\hline \multicolumn{6}{|l|}{ Words and expressions } \\
\hline $\begin{array}{l}\text { - I feel inclined to use certain language/slang } \\
\text { from the games I played when talking to people } \\
\text { in real life. }\end{array}$ & .713 & & & & \\
\hline $\begin{array}{l}\text { - I never use abbreviations and expressions I } \\
\text { learned in my game when talking to people in } \\
\text { "real life". }\end{array}$ & -.832 & & & & \\
\hline $\begin{array}{l}\text { - I never use abbreviations and expressions I } \\
\text { learned in my game when talking to other } \\
\text { gamers (while not playing the game). }\end{array}$ & -.809 & & & & \\
\hline $\begin{array}{l}\text { - When thinking out loud, it happens that I use } \\
\text { terms, expressions or abbreviations I picked up } \\
\text { in a computer game. }\end{array}$ & .723 & & & & \\
\hline $\begin{array}{l}\text { - I have NEVER noticed myself using or thinking } \\
\text { slang from a computer game after I turned it off. }\end{array}$ & -.766 & & & & \\
\hline Eigenvalues & 6.98 & 2.36 & 2.08 & 1.83 & 1.64 \\
\hline$\%$ Variance - factor & 31.71 & 10.71 & 9.45 & 8.31 & 7.46 \\
\hline$\%$ Variance - cumulative & 31.71 & 42.42 & 51.87 & 60.19 & 67.65 \\
\hline
\end{tabular}

Note. Factor loadings of less than .300 have been omitted.

distinguished. We conducted an exploratory factor analysis, employing Principal Component analysis with a Varimax rotation, on all the items related to each of the five biased perceptions and experience dimensions included in the survey (a total of 22 items). Results revealed a five-factor solution explaining $67.65 \%$ of the total variance. These five factors nicely represented the five proposed dimensions of biased perceptions and experiences and every item used to assess the dimension loaded high on that specific dimension. In addition, internal consistency tests of the different items for each of the five dimensions were very satisfactory (all Cronbach $\alpha$ values $>.70$ ). A detailed output of the rotated component matrix obtained in the factor analysis can be found in Table 1. This table shows all items used to tap into the game-biased perceptions and associations and their corresponding factor loadings. All specific items showed high loadings $(>|.6|)$ on the corresponding specific dimension. From these results we concluded that the five domains we proposed in the introduction can be empirically distinguished as five separate domains.

We then composed five new variables by computing the average score from the items for each of the five different domains. The five domains showed significant but only moderate positive correlations (all $r$ values $<.42$, see Table 2 ). This means that the dimensions are related, but not similar.

Mean scores for the five domains were high (all $M$ values > 3.05), indicating that, on average, the dimensions do occur in the players from our sample. One sample $t$-test 
Table 2. Correlation matrix of the five game-biased perceptions and association dimensions.

\begin{tabular}{llllll}
\hline & $\begin{array}{l}\text { Physical } \\
\text { objects }\end{array}$ & $\begin{array}{l}\text { Sounds and } \\
\text { music }\end{array}$ & $\begin{array}{l}\text { Words and } \\
\text { expressions }\end{array}$ & Daydreams & $\begin{array}{l}\text { Nightly } \\
\text { dreams }\end{array}$ \\
\hline Physical objects & 1.00 & & & & \\
Sounds and music & $.41^{* * *}$ & 1.00 & & & \\
Words and expression & $.38^{* * *}$ & $.32^{* * *}$ & 1.00 & 1.00 & \\
Daydreams & $.31^{* * *}$ & $.25^{* * *}$ & $.33^{* * *}$ & $.39^{* * * *}$ & 1.00 \\
Nightly dreams & $.3^{* * *}$ & $.31^{* * *}$ & $.35^{* * *}$ & & \\
\hline
\end{tabular}

$* * * p<.00 \mathrm{I}(\mathrm{N}=5 \mathrm{II})$.

Table 3. T-test results of game-biased perceptions and associations against the neutral midpoint of the rating scale.

\begin{tabular}{lllcl}
\hline & Mean & SD & t-value & Cohen's d \\
\hline Physical objects & 3.31 & 0.97 & $7.22^{\text {***k }}$ & 0.32 \\
Sounds and music & 3.28 & 1.16 & $5.37^{\text {*** }}$ & 0.24 \\
Vocabulary and expressions & 3.28 & 1.12 & $5.61^{\text {*⿰冫欠 }}$ & 0.25 \\
Daydreams & 3.67 & 0.90 & $16.86^{* * *}$ & 0.75 \\
Nightly dreams & 3.06 & 1.08 & 1.32 & 0.06 \\
\hline
\end{tabular}

${ }^{a}$ One sample $t$-test (two-tailed) with test-value 3 on a scale ranging from I to 5 .

$* p<.05 ; * * p<.01 ; * * * p<.001$.

comparing the means with a value of " 3 ", which was the neutral point on the scale, revealed significant differences for four of the five dimensions. Concretely, these results showed that, over our total sample, respondents indicated to agree more than just neutrally that the game-biased perceptions related to physical objects, sounds and music, vocabulary and expressions and daydreams happened to them. Only nightly dreams did not differ significantly from the neutral point of the scale, neither in a positive nor in a negative way. Table 3 shows these results in detail. These results largely confirm Hypothesis 1, in that all but one of the five domains we hypothesized to be affected by game-biased perceptions and associations were indeed affected in our sample of avid players of MMORPGs.

Next, we tested our second and third hypotheses that the occurrence of game-biased perceptions and associations is reinforced with playing frequency and narrative involvement. First of all, we checked for correlations between these two parameters. These appeared to be significant but low $(r=.13, p<.003)$, thus reducing the risk of multicollinearity. Next, we conducted five regression analyses, each with one of the five dimensions of the biased perceptions and experiences as the dependent variable and playing frequency and narrative involvement as predictors. Results showed that playing frequency is positively related to the occurrence of biased perceptions in all five domains. This means that the more time a player invests in the game the stronger the game-biased perceptions and associations become. This confirms Hypothesis 2. Involvement in the storyline had a weaker, albeit positive relation with three of the five domains, being 
Table 4. Regression results for the relation between playing frequency and narrative involvement on the five game-biased perceptions and associations.

Dimension $\beta(t)$

\section{Physical objects}

Playing frequency .I $30(2.94)^{* * *}$

Model: $F=8.37, p<.001$, adj. $R^{2}=.032$

Narrative involvement $.107(2.42)^{*}$

\section{Sounds and music}

Playing frequency .I 39 (3.22) (*** $^{\text {*** }}$

Model: $F=18.48, p<.001$, adj. $R^{2}=.064$

Narrative involvement $.202(4.68)^{\text {*adk }}$

Words and expressions

Playing frequency $.288(6.76)^{\text {**k }}$

Narrative involvement .08I (1.9I)

Model: $F=26.85, p<.00 \mathrm{I}$, adj. $R^{2}=.092$

Daydreams

Playing frequency . I7I (3.87)

Narrative involvement .03I (0.7I)

Model: $F=8.27, p<.00 \mathrm{I}$, adj. $R^{2}=.028$

Nightly dreams

Playing frequency .II $8(2.68)^{* *}$

Narrative involvement $.096(2.17)^{*}$

Model: $F=26.85, p<.00$ I, adj. $R^{2}=.092$

$* p<.05 ; * * p<.01 ; * * * p<.001$ (two-tailed).

association with physical objects, sounds and music, and nightly dreams. This means that these three dimensions of game-biased perceptions and association become stronger if a player gets more involved in the story of the game. This partially confirms Hypothesis 3 , in which we predicted this effect for all five domains of game-biased perceptions and associations. A detailed outline of the results can be found in Table 4.

\section{Discussion and conclusion}

The research findings reported in this paper are novel and highly relevant to the field of game studies. Over recent years, numerous studies have focused on explicit positive or negative effects of playing digital games, but our study clearly shows that playing digital games can also induce quite profound effects on everyday experiences and perceptions, which are neither inherently positive nor negative. Moreover, the large majority of studies reporting explicit effects of playing digital games rely on short-term changes in emotions, cognitions or behaviours observed in a lab context. In this paper, we outlined how playing digital games can also establish enduring effects in terms of perception and associations as they occur in everyday life and we identified these in a large-scale survey with WoW players. Results from this survey, based on a factor analysis, showed that the five domains in which we expected game-biased perceptions and associations to occur can be 
empirically distinguished as five separate domains. This complements earlier findings from a focus group study in which the authors also distinguished these five domains through an exploratory qualitative analysis (Poels et al., 2010). Furthermore, our results are in line with the hypothesis, inspired by theories and findings in the areas of brain plasticity and perceptual sets, that the occurrence of game-biased perceptions and associations is reinforced with increasing playing frequency. The results also indicate that higher levels of narrative involvement, a qualitative measure of intense game play, mildly increase the occurrence of the biased perceptions and experiences, but not with respect to game-related slang and daydreaming. It can thus be concluded that intensively and repeatedly playing digital games can have an influence on how players perceive objects, sounds and persons in our daily life, and how elements from the game may penetrate conversations and/or (day)dreams.

Although we found significant positive relations supporting our hypotheses related to playing frequency and narrative involvement, the strength of these relations and the explained variance for all five domains was somewhat weak. This means that definitely not all variance in the game-biased perceptions and associations is due to differences in playing frequency and narrative involvement. We are fully aware that other factors than the ones we proposed may contribute to the occurrence of the five perception and experience domains. We expect that there are a number of individual and contextual differences between the players from our sample that also contribute to variations in the occurrence of the biased perceptions and experiences. For example, there probably are individual differences in the extent and the intensity to which people have nightly dreams and are able to recall those dreams in the morning. The same holds for daydreaming; some people do this more often than others (Singer and McCraven, 1961) and this will have an impact on daydreams related to gaming, accordingly. Further, the personal context or the situation in which a player lives might also have an impact. For example, college students probably have more time for daydreaming than people with a full-time job, and also have more occasions to engage in informal conversations than older people, who more strictly have to adhere to their formal role at work or as a parent. Besides difference due to varying occupations between young and older players, age in itself can be related to the formation of perceptual sets. Young people's brains are still much more plastic and impressionable compared to the adult brain (Kolb et al., 1998). As such, the young brain is still much more shaped by varying conditions of external simulation and exposure to new environments. Also, since the current study only relied on self-report of explicit, consciously experienced effects, it could be that implicit, subconscious effects (e.g., dreams that one does not remember) did not surface. Further studies are needed to test whether this applies to exposure to virtual worlds like MMORPGs. In sum, we expect a range of factors to contribute to coloured perception of habitual gamers. The important and relevant conclusion that can be drawn from the current study is that, inspired by findings from perception theory and brain plasticity, the occurrence of biased perceptions and experiences is reinforced by an increase in playing time and heightened involvement in the storyline of the game, two factors that presumably lead to a higher activation of perceptual sets stemming from the game environment.

The fact that we only included habitual players of a specific game, WoW, might impose a limitation to our study. WoW players are typically avid gamers and serious 
engagement in the game, which is necessary in order to fully enjoy the game, requires heavy play. As such, it is difficult to find players who play WoW on an irregular or casual basis. Accordingly, we could not compare our findings to less habitual players, which might also partly explain our relatively weak relationships. It could be that the degree of perceptual stimulation from the game environment that is necessary in order for biased perceptions and experiences to occur is lower than the minimum degree of perceptual stimulation that was present in the gamers from our sample. For future studies, it would be interesting to pick a game (genre) that enables both casual and heavy game play and compare the differences in the occurrence of biased perceptions and experiences for both play styles and frequencies of play.

This study focused on MMORPGs as one particular genre of digital games. We expect the concrete manifestation of these long-term biased perceptions and experiences to depend on the type of game or game genre one is repeatedly engaging in. This means frequent players of first person shooter (FPS) games will probably experience different things, make other associations and use other game-related slang, compared to habitual players of MMORPGs. Exploring biased perceptions for habitual FPS players, both through qualitative and quantitative studies, and comparing the nature and the degree of this phenomenon between different game genres would be an interesting starting point for future research.

The main research findings from this study are related to findings from the field of cultivation studies. The central premise of cultivation studies is that heavy users of a particular medium (e.g., television, movies) are more likely to make estimations about the real world based on how the world is displayed in their favourite medium (Van Mierlo and Van den Bulck, 2004). This means cultivation studies also make a link between perceptions in the game world and real-life perceptions. The main differences between our approach and the approach within cultivation studies is that we test general phenomena related to how players perceive everyday things, whereas a cultivation approach generally tries to make predictions about specific content and perceptions (e.g., whether being exposed to weapons in a game increases your estimation of weapon use in real life). We did not try to reveal how game elements may influence specific estimations or attitudes about similar real-life elements. It would be interesting to further explore how the biased perceptions and experiences, as described in this paper, relate to the occurrence of such specific cultivation effects.

This paper showed that prolonged exposure to structures from a specific game environment, such as the MMORPG WoW, has the potential to influence our everyday thoughts and perceptions. We have linked this phenomenon to the creation of perceptual sets based on the game environment, which bias the everyday perceptions and experiences of players of that game. In order to fully integrate and empirically illustrate the concept of perceptual sets and brain plasticity, additional steps need to be taken in future research. We could, for example, think of brain imaging studies, in line with Munte et al. (2002) and Draganski et al. (2006), comparing the brain structures of habitual players with those of non players. We see our current approach as an important addition to current gaming research, since it focuses on digital gaming as an everyday leisure activity, away from its explicit and normative associations of being "a good or bad thing to do". This probably also fits well with the intuitive and experiential lay-conceptions of players 
themselves about their favourite pastime. In fact, there might be a positive note to this story, as research has shown that dreaming about the game improves performance (Stickgold, in Callaway, 2009).

\section{Acknowledgements}

The authors are indebted to the anonymous reviewers for their valuable comments on earlier versions of this manuscript and to Bart Van Iersel for his help with the data collection.

\section{Funding}

This research received no specific grant from any funding agency in the public, commercial or not-for-profit sectors.

\section{References}

Blizzard Entertainment (2004) World of Warcraft (Computer Game).

Boellstorff T (2008) Coming of Age in Second Life - An Anthropologist Explores the Virtually Human. Princeton, NJ/Oxford: Princeton University Press.

Boring E (1930) A new ambiguous figure. American Journal of Psychology 42: 444.

Brake M (1980) Sociology of Youth Culture and Youth Subcultures: Sex, Drugs and Rock 'n' Roll? London: Routledge \& Kegan Paul PLC.

Bruner J and Potter M (1964) Interference in visual recognition. Science 144(361): 424-425.

Bugelski B and Alampay D (1961) The role of frequency in developing perceptual sets. Canadian Journal of Psychology 15(4): 205-211.

Callaway E (2009) Dreams of Doom help gamers learn. Available at: http://www.newscientist. com/article/dn18082-dreams-of-doom-help-gamers-learn.html (accessed 15 November 2011).

Calleja G (2007) Digital game involvement: a conceptual model. Games and Culture 2(3): 236-260.

Calleja G (2011) In-Game: From Immersion to Incorporation. Cambridge, MA: MIT Press.

Carnagey N and Anderson C (2005) The effects of reward and punishment in violent video games on aggressive affect, cognition, and behavior. Psychological Science 16(11): 882-889.

CCP Games (2003) Eve Online (Computer Game).

Cohen A (1998) The functions of music in multimedia: a cognitive approach. Proceedings of the 5th International Conference on Music Perception and Cognition 5: 13-20.

Cole H and Griffiths M (2007) Social interactions in massively multiplayer online role-playing gamers. Cyberpsychology \& Behavior 10(4): 575-583.

Csikszentmihalyi M (1990) Flow: The Psychology of Optimal Experience. New York: Harper \& Row.

Dauphin B and Heller G (2010) Going to other worlds: the relationship between videogaming, psychological absorption, and daydreaming styles. Cyberpsychology, Behavior, and Social Networking 13(2): 169-172.

Draganski B, Gaser C, Kempermann G, et al. (2006) Temporal and spatial dynamics of brain structure changes during extensive learning. Journal of Neuroscience 26(23): 6314-6317.

Dye M, Green C and Bavelier D (2009) The development of attention skills in action video game players. Neuropsychologia 47: 1780-1789.

Earling A (1996) Do computer games fry your brain? Available at: http://archives.citypaper.net/ articles/032196/article038.shtml (accessed 22 August 2011).

Ermi L and Mäyrä F (2005) Fundamental components of the gameplay experience: analysing immersion. In: Changing Views: Worlds in Play, selected papers from the 2005 DiGRA conference, Vancouver, British Columbia, Canada, 16-20 June, 2005. 
Ferguson CJ (2007) The good, the bad and the ugly: a meta-analytic review of positive and negative effects of video games. Psychiatry Quarterly 78: 309-316.

Ferguson CJ (2010) Blazing angels or resident evil? Can violent video games be a force for good? Review of General Psychology 14(2): 68-81.

Gackenbach J (2006) Video game play and lucid dreams: implications for the development of consciousness. Dreaming 16(2): 96-110.

Gamasutra(2011)WorldofWarcraftsubscriptionscontinuetodecline, thoughmoreslowly. Availableat: http://www.gamasutra.com/view/news/36351/World_of_Warcraft_Subscriptions_Continue_ To_Decline_Though_More_Slowly.php (accessed 29 August 2012).

Green $\bar{C}$ and Bavelier D (2003) Action video game modifies visual selective attention. Nature 423: 534-537.

Green C and Bavelier D (2007) Action-video-game experience alters the spatial resolution of vision. Psychological Science 18(1): 88-94.

Gregory R (1970) Intelligent Eye. West Sussex: Littlehampton Book Services Ltd.

Jennett C, Cox A, Cairns P, et al. (2008) Measuring and defining the experience of immersion in games. International Journal of Human-Computer Studies 66(9): 641-661.

Kidd G (1996) Possible futures of virtual reality. Available at: http://catless.ncl.ac.uk/Risks/17.78. html\#subj1 (accessed 22 August 2011).

Klinger E (1990) Daydreaming: Using Waking Fantasy and Imagery for Self-Knowledge and Creativity. Los Angeles, CA: J. P. Tarcher.

Kolb B and Whishaw IQ (1998) Brain plasticity and behavior. Annual Review of Psychology 49: 43-64.

Kolb B, Forgie M, Gibb R, et al. (1998) Age, experience and the changing brain. Neuroscience \& Behavioral Reviews 22(2): 143-159.

Maguire EA, Woollett K and Spiers HJ (2006) London taxi drivers and bus drivers: a structural MRI and neuropsychological assessment. Hippocampus 16: 1091-1101.

Mojang (2009) Minecraft (Computer Game).

Munte T, Altenmuller E and Jancke L (2002) The musician's brain as a model of neuroplasticity. Nature Reviews Neuroscience 3(6): 473-478.

Nardi BA (2010) My Life as a Night Elf Priest. Ann Arbor, MI: University of Michigan Press.

Pajitnov A (1984) Tetris (Computer Game).

Pennebaker JW, Mehl MR and Niederhoffer KG (2003) Psychological aspects of natural language use: our words, our selves. Annual Review of Psychology 54(1): 547-577.

Poels K, de Kort Y and IJsselsteijn W (2012) Identification and categorization of digital game experiences: A qualitative study integrating theoretical insights and player perspectives. Westminster Papers in Communication \& Culture 9(1): 107-129.

Poels K, IJsselsteijn W, de Kort Y, et al. (2010) Digital games, the aftermath: qualitative insights into post game experiences. In: Bernhaupt R (ed.) Evaluating User Experience in Games. Berlin: Springer, pp. 149-164.

Reeves B, Malone T and O'Driscoll T (2008) Leadership in online labs. Harvard Business Review, May, pp. 1-9.

Riot Games (2009) League of Legends (Computer Game).

Singer LS and McCraven VG (1961) Some characteristics of adult daydreaming. Journal of Psychology: Interdisciplinary and Applied 51(1): 151-164.

Steinkuehler C and Williams D (2006) Where everybody knows your (screen) name: online games as "third places." Journal of Computer-Mediated Communication 11(4): 885-909.

Stickgold R, Malia A, Maguire D, et al. (2000) Replaying the game: hypnagogic images in normals and amnesics. Science 290(5490): 350-353. 
Valkenburg P and Van der Voort T (1995) The influence of television on children's daydreaming styles - a 1-year panel study. Communication Research 22(3): 267-287.

Van den Bulck J (2004) Media use and dreaming: the relationship among television viewing, computer game play, and nightmares or pleasant dreams. Dreaming 14(1): 43-49.

Van Mierlo J and Van den Bulck J (2004) Benchmarking the cultivation approach to video game effects: a comparison of the correlates of TV viewing and game play. Journal of Adolescence 27(1): 97-111.

Williams D (2006) Virtual cultivation: online worlds, offline perceptions. Journal of Communication 56(1): 69-87.

Williams D, Yee N and Caplan S (2008) Who plays, how much, and why? Debunking the stereotypical gamer profile. Journal of Computer-Mediated Communication 13(4): 993-1018.

Yee N (2006a) The demographics, motivations, and derived experiences of users of massively multi-user online graphical environments. Presence-Teleoperators and Virtual Environments 15(3): 309-329.

Yee N (2006b) The labor of fun: how video games blur the boundaries of work and play. Games and Culture 1(1): 68-71.

Yee N (2006c) Motivations for play in online games. Cyberpsychology \& Behavior 9(6): 772-775.

\section{Author biographies}

Karolien Poels is associate professor of Strategic Communication at the Department of Communication Studies, University of Antwerp, Belgium. She is a member of the research group MIOS (Media \& ICT in Organizations \& Society). Her core research topics include: (1) advertising and consumer psychology and (2) digital media (games, social network sites). Emotions form the central topic in most of her studies. Her gaming research is currently focused on player emotions and experiences in relation to game evaluations and preferences, player involvement, morality and in-game advertising.

Wijnand A Ijsselsteijn is full professor of Cognition and Affect in Human-Technology Interaction at Eindhoven University of Technology in The Netherlands. He has a background in cognitive neuropsychology and artificial intelligence. In 2004, he received his $\mathrm{PhD}$ from Eindhoven University of Technology (TU/e) on the topic of telepresence. His focus is on conceptualizing and measuring human experiences in relation to advanced media environments (immersive threedimensional media, serious games, affective computing) in the service of human learning, communication, health and wellbeing.

Yvonne de Kort is associate professor of Environmental Psychology in the research group Human-Technology Interaction at Eindhoven University of Technology. Traditionally, environmental psychology deals with interactions between humans and their physical and social environment, yet her work centres on domains where people, spaces and technology meet. Her research focuses most on social interaction, wellbeing and health of people in virtual, mediated or technologically augmented spaces. She is manager of the Sound Lighting program line of the Intelligent Lighting Institute (ILI) and co-director of the Game Experience Lab. 